\title{
Do You Get What You Pay for? Assessing the Use of Prison from an
}

\section{Economic Perspective}

\author{
KEVIN MARSH, CHRIS FOX and CAROL HEDDERMAN
}

Abstract: This article assesses the relative economic costs and benefits of alternative sentences. A conceptual economic model is developed in which the benefits are the rehabilitation, incapacitation, deterrence and retribution effects of prison. A review of the literature was undertaken to identify economic studies that measure these effects. The evidence available tends to focus on costs and the rehabilitation and incapacitation effects. The evidence on the deterrence effect takes two forms - theoretical models and empirical analysis. Little economic evidence on the retribution effect of prison was identified. In conclusion, whatever the other reasons put forward for or against the use of prison, it is reasonable to conclude that using it for anyone but those convicted of serious offences is a waste of public resources.

Keywords: prison; economic; cost-benefit analysis; rehabilitation; incapacitation; deterrence; retribution

\section{Introduction}

Over the last 15 years the prison population has risen from 44,000 to over 83,000 a rise of $88 \%$. The operating costs associated with managing a prison population of this size are around £2 billion and the government has recently announced plans to spend an additional £3.8 billion on providing a further 20,000 spaces by 2014 . Anyone who argues that this is not money well spent risks being accused of being soft on crime and uninterested in the consequences for victims (Hedderman 2008). But an economic analysis can not only take the actual victim costs of offences into account, but consider the savings to victims which might accrue from favouring one sentence over another. It is, therefore, a good time to ask whether sending people to prison is worth the cost; and how far the alternatives offer better or worse value for money.

Justifications for sentencing take two main forms. Retributive justifications look back at the offence and express disapproval for what has happened in the form of punishment. The penalty is usually expected to be proportionate to the offence and the offender's degree of culpability. Utilitarian justifications focus on the expected impact of a sentence to reduce the chances of such an act being committed again by the same offender, other offenders or both (Hedderman 2007). Any individual sentence can, of course, be imposed with 
both punishment and crime reduction in mind. In the case of imprisonment Dilulio (1996) suggests that its use:

. . offers at least four types of social benefits. The first is retribution: imprisoning Peter punishes him and expresses society's desire to do justice. Second, is deterrence: imprisoning Peter may deter either him or Paul or both from committing crimes in the future. Third is rehabilitation: while behind bars, Peter may participate in drug treatment or other programs that reduce the chances that he will return to crime when free. Fourth is incapacitation: from his cell, Peter can't commit crimes against anyone save other prisoners, staff or visitors. (p.18)

The Criminal Justice Act 2003 sets out the purposes of sentencing (Section 142(1)) and makes clear reference to both reductivist and retributivist rationales. Prior to the Criminal Justice Act 2003, the extent to which one or more of these principles was reflected in an individual sentence varied; and might be no more than the implicit or explicit aspirations of the sentencer, which might or might not be shared by the offender, the victim, the supervising service or the wider public. The lack of a direct or simple connection between the purpose of sentencing and outcome may be one of the reasons that research into the impact of sentencing has been relatively rare. Another reason is that some of these aims are very hard to measure. For example, despite the considerable conceptual differences in how incapacitation and deterrence are expected to operate, the lack of adequate or agreed measures for either aim means that reviews tend to conclude that their effects are not distinguishable from one another (Nagin 1998; Von Hirsch et al. 1999; Carter 2003; Bottoms 2004). In both cases reconviction rates are used to assess change because it is 'the only readily accessible measure of reoffending' (Friendship et al. 2004, p.10).

Two recent developments mean that it is both timely and possible to take a fresh look at sentencing effectiveness. The first is that, in putting the aims of sentencing on a statutory footing, the Criminal Justice Act 2003 also redefined those aims as being the:

- punishment of offenders;

- reduction of crime (including its reduction by deterrence);

- reform and rehabilitation of offenders;

- protection of the public; and

- making of reparation by offenders to persons affected by their offence.

This redefinition is important in two respects. First, it introduced a specific acknowledgement of the victim's perspective by according reparation 
equivalent status to other sentencing aims. Second, the legislation drew attention to the potential impact sentencing might have in terms of crime reduction and public protection (Hedderman 2007).

The second development is that economic evaluations of criminal justice interventions, which have historically focused on a fairly narrow range of issues such as the cost-benefit of early interventions (for example, Parks 2000), are now being conducted in relation to issues such as target hardening crime prevention measures (for example, Bowers, Johnson and Hirschfield 2004). Recent work, particularly by Aos et al. (2001) in the US and Marsh and Fox (2008) in the UK, has further expanded the field to cover cost-benefit analyses (CBAs) of criminal sanctions. This recent work also uses more rigorous and sophisticated analytic techniques than did the earlier work, for assessing both the costs and benefits of different sentences, and interventions within a sentence. This development perhaps reflects the fact that the earlier work was generally conducted by criminologists with a little economic knowledge or advice rather than by economists with some criminological knowledge and advice.

In this article we review economic studies to ask whether, from an economic perspective, prison is effective? We start by reviewing recent CBA of the effectiveness of prison. While the CBAs undertaken vary in the types of the benefits of prison they capture, at best they only capture incapacitation, rehabilitation and specific deterrence effects. The remaining sections turn to economic evidence on the other effects of prison. We review both the economic theory and the studies that attempt to describe and measure general deterrence effects. We also include a brief discussion of economic perspectives on retribution. Finally we draw conclusions about whether prison represents an efficient use of public resources and suggest areas on which future economic enquiry should focus.

\section{Cost-Benefit Analysis (CBA)}

\section{What Does a CBA Add to the Debate about the Use of Prisons?}

CBA is concerned with both measuring the effectiveness of an intervention and whether an intervention is efficient in that the benefits of the intervention are greater than the costs (Barnett and Escobar 1987; Dhiri and Brand 1999; Cohen 2000; Welsh and Farrington 2000; Roman and Butts 2005; Swaray, Bowles and Pradiptyo 2005). In a CBA, the effects - the outcomes of an intervention - are valued in standardised monetary units, such as the dollar or the pound, and compared with the costs of the intervention's inputs. This approach allows for a direct comparison of two or more interventions, even if those interventions vary in their goals and objectives and target heterogeneous populations and outcomes.

Economists put forward a number of arguments in favour of analysing the costs and benefits of criminal justice interventions. First, even though an intervention may yield 
positive outcomes (such as desistance from crime and increases in pro-social behaviour such as getting a job) the cost of the intervention may outweigh the intervention's benefits; and an alternative intervention may achieve the same outcomes for a lower cost. Second, whereas observational studies examine outcomes one at a time, CBA considers all outcomes jointly, using the standardised (monetised) estimates of costs and benefits as weights that generate a single measure of intervention effectiveness. Third, CBA allows for the valuation of hard-to-observe outcomes, such as fear, pain and suffering. Fourth, CBA has the potential to account for externalities - outcomes for individuals not directly involved in the intervention, but who are nevertheless affected by its results. Finally, since public resources are scarce, it is incumbent upon policy makers to choose the most efficient intervention, that is, the scheme where costs are minimised and benefits are maximised (Cohen 2000).

Marsh, Chalfin and Roman (2008) have illustrated the importance of CBA to decision making in criminal justice. They demonstrate that the effect of a criminal justice intervention at reducing offending is only weakly related to net benefits in terms of savings to the Exchequer and/or wider society and that in about one-quarter of cases, considering both costs and benefits would produce a different policy recommendation as opposed to just analysing changes in offending rates.

Despite the advantages of CBA, to date there have been few economic evaluations of criminal justice interventions (Dilulio 1996; Cohen 2000; Brown 2004; Bushway and Reuter 2005). This dearth of economic analysis is illustrated by McDougall et al.'s (2003) review of economic analysis of sentencing options, which identified just nine CBAs.

This lack of economic analysis in criminal justice is in contrast to a number of other policy areas, in particular health care. In the UK, all new health technologies have to be approved by the National Institute for Health and Clinical Excellence (NICE). As part of the appraisal undertaken by NICE to inform their recommendations, an economic analysis is undertaken to determine both the costs and benefits of the new interventions. NICE employ a costeffectiveness threshold to ensure that NHS resources are spent only on health technologies that increase the overall health-related quality of life of patients (see NICE 2007).

\section{What do CBAs of Imprisonment Tell Us?}

The economics literature includes two approaches to measuring the costs and benefits of sentencing options. Primary studies of the type reviewed in McDougall et al. (2003) are based on the collection of primary data. A second approach is to review existing effects studies and then build economic models based in part on data from such a review. 
McDougall et al. (2003) reviewed studies of the cost-benefits of sentencing options. They carried out structured searches of studies carried out between 1980 and 2001 using nine electronic databases, as well as consulting experts in the field. The search identified only two CBAs of imprisonment, both undertaken in the USA. In the first of these, Gray and Olson (1989) assessed the cost-benefit of prison for burglars, and included the rehabilitation and specific deterrence effect of prison in the analysis. The study found that every one dollar spent on prison produced only $\$ 0.24$ of avoided offending. In contrast, for burglars given a probation sentence, every dollar spent on the sentence produced $\$ 1.70$ of avoided offending. While this result would suggest that probation is preferable to prison as a sentence for burglars, there are caveats to drawing this conclusion. First, a before/after study was employed to measure the changes in offending resulting from the sentences, meaning that any variation in effect may be due to differences in the characteristics of the offenders receiving the interventions. Second, the economic analysis undertaken was judged by McDougall and colleagues to have been incomplete, as it did not attempt to capture the intangible victim costs of pain and suffering.

The second CBA study identified by McDougall et al., conducted by Piehl and Dilulio (1995), assessed the cost-benefit of prison for different types of offenders compared with doing nothing, but considered only the incapacitation effect of prison. They found that, for offenders who committed twelve crimes or more a year, every one dollar spent on prison produced $\$ 2.80$ of avoided offending. However, for all offenders the benefit reduced to $\$ 0.36$. This would suggest that prison is an efficient sentencing option for only the more serious offenders. Piehl and Dilulio concluded that prison pays for most state prisoners who comprise either violent or repeat offenders and/or who present a real danger to the physical safety or property of their community. However, for offenders committing auto thefts at a rate of three a year, burglaries at a rate of six a year, and petty thefts at a rate of 24 a year, costs of imprisonment outweighed the social benefits of imprisonment. This was particularly true of those convicted of drug offences. Once again, this conclusion is subject to caveats. While the economic analysis was judged by McDougall et al. (2003) to have been complete, and the authors did attempt to measure the intangible costs of pain and suffering, the analysis captured only incapacitation effects. Furthermore, changes in offending were assessed by assuming that prerelease rates of self-reported offending would have been maintained had the offender not been incarcerated. This approach is not generally considered reliable as it relies on the assumption that offenders would continue to offend at the same rate if they were not incarcerated. This ignores 'maturation, spontaneous remission or regression to the mean' ${ }^{1}$ (Hedderman and Hough 2005, p.60). 
A key limitation with the CBAs identified by McDougall et al. (2003) is that the follow-up periods for measuring recidivism were relatively short. In response to these limitations and others, two recent studies have used a different approach to estimate the efficiency of prisons - building economic models onto reviews of effect studies.

Aos et al. (2001) and Aos, Miller and Drake (2006) were commissioned by the Washington State Legislature to investigate the cost-effectiveness of different sentencing options. They conducted a review of research to identify what works to reduce crime. The estimates of short-term changes in offending rates identified in this review were then extrapolated over time using data on the relationship between age and crime. These long-term changes in offending were then valued, taking account of both the cost to the public sector and to victims. These estimates of the value of sentencing options were then compared to the costs of the sentencing options to determine whether they represented efficient use of public money.

One of the interventions considered by Aos et al. (2001) and Aos, Miller and Drake (2006) is prison. Evidence from six methodologically rigorous effectiveness studies suggested that, following intensive probation, juvenile offenders commit as many crimes as if they had received a custodial sentence. However, as intensive probation costs on average $\$ 18,854$ less than incarceration, it was concluded the probation was a more efficient use of public resources. Similarly, evidence from three welldesigned and conducted studies of effectiveness for adult offenders found that adults commit as many crimes after intensive supervision as they would after receiving a custodial sentence. However, as intensive supervision costs on average $\$ 5,925$ less than incarceration, it was concluded that supervision is a more efficient use of public resources. A similar method was adopted by Marsh and Fox (2008), but to estimate the costs and benefits of prison in England and Wales. The model estimated the net benefit of non-custodial sentences for adult and juvenile offenders when compared with custodial sentences, and captured the incapacitation, rehabilitation, and specific deterrence effects. For those sentences for which statistically significant differences in post-sentence offending were identified, non-custodial sentences were found to produce a net benefit when compared with custodial sentences. Specifically, residential drug treatment, surveillance (for example, electronic monitoring), and surveillance combined with drug treatment were found to both cost less and to reduce offending when compared with prison.

Marsh and Fox (2008) identified some caveats that must be borne in mind when applying their results to inform policy making. First, while the study attempted to focus on UK-based data, the majority of evidence of effect came from studies undertaken in the USA, calling into question the transferability of the results to the UK. Second, there was a limited number of studies that assessed the relative effectiveness of custodial and noncustodial sentences and that met the tight methodological criteria used during the literature review. Third, there was heterogeneity in the effects identified in these studies. 
To summarise, the existing CBAs suggest that prison is an inefficient sentencing option. However, where the analysis differentiates between offender types, it suggests that prison may be efficient for more serious offenders.

\section{Deterrence}

One of the gaps in the CBA summarised in the previous section is that it does not capture the general deterrent effect of imprisonment. Economists consider deterrence using both theoretical models and empirical (mainly econometric) evidence.

\section{Economic Models of Deterrence}

Why do people commit crime? Why do they commit particular crimes? Can we explain the amount of crime that is committed? Traditionally the domain of criminologists, these questions have increasingly caught the attention of economists. In 1968, as part of a larger model designed to explore optimal criminal justice policy, Becker (1968) developed the 'supply of offense' function. He argued that those who offend, just like anyone else, are rational agents trying to maximise their expected utility. That is, an individual will commit an offence if the expected utility of doing so is positive, and will not if it is negative. Whether the utility of doing so is positive or negative depends on the relative size of the benefits of committing a crime (the expected income it generates) and the cost of committing a crime (the expected punishment).

Eide (1999) outlines the development of this basic model since it was first proposed by Becker and the implications of these developments for our understanding of the magnitude of the deterrence effect. The simplest version of the model identified by Eide views the choice to undertake legal or illegal activities from the perspective of 'portfolio choice' models. Here individuals are seen as choosing to invest their time between activities with different risks and rewards. Illegal activities are considered risky because of the uncertainty about sanctions. Within this model, the direction and magnitude of the deterrence effect depends on the attitude of individuals towards risk. If individuals are risk averse, then increases in either the probability or severity of punishment will deter crime. However, if individuals are risk-loving, then the effect of an increase in the severity of a sanction is uncertain. An increase in severity will reduce the expected gains from crime, which will produce two effects: a substitution away from crime to legal activities that are now relatively more lucrative; and an increase in criminal activity to maintain 'income' levels now that returns are lower. The overall effect on crime is indeterminate.

A different type of model perceives the choice to commit a crime as the allocation of time, rather than money or wealth, between legal and illegal activities. Within these models individuals choose to either specialise in legal or illegal activities or 
undertake a mix of the two. The allocation of time between activity types will depend on the monetary and monetised benefits and costs of activities, and an increase in the probability or severity of sanctions will affect the optimal mix of activities. The effect of increases in the probability or severity of punishment depends on whether leisure time is assumed to be fixed or not fixed. Assuming that leisure time is not fixed, the same results as for the portfolio choice model are obtained. However, assuming that leisure time is fixed causes the effect of changes in the severity of sanctions to become inconclusive.

Underlying all of these models is a variation of rational choice theory. ${ }^{2}$ One critique of the rational choice model is that it is an inadequate explanation of behaviour as people have insufficient information about the environment and the outcomes of actions to make genuinely rational decisions. This criticism has caused economists to suggest that the theory of bounded rationality may be a better representation of offenders' behaviour than the rational choice theory (see Nagin and Paternoster 1993).

Other critiques of rational choice theory range from outright rejection in favour of normative explanations of behaviour to suggestions that rational choice theory is inadequate because people's behaviour is determined by procedural rationality - where people follow rules established by history or social relations - or by expressive rationality - where people demonstrate their self-conception and worth by participating in symbolic acts (Eide 1999). So, for example, it has been argued that rational choice theory is better at explaining offences which can be monetised than expressive offences such as domestic violence (Trasler 1993). Some variations of the model have relaxed the monetising assumption. However, these models produce more ambiguous results regarding the impact of punishment on criminal activity.

This is not the place to resolve this debate. However, it is important to elaborate what is entailed by applying the theory of rational choice to criminal behaviour. As Becker (1968) himself put it:

. . . a useful theory of criminal behavior can dispense with special theories of anomie, psychological inadequacies, or inheritance of special traits and simply extend the economist's usual analysis of choice. (p.170)

It is perhaps this dismissal of the importance of social norms and hence political and moral dimensions that characterises the distinction between economic and criminological theories. Eide (1999) describes economic theories as assuming preferences to be constant, and individuals as choosing between courses of action to best satisfy these preferences, given the incentives offered by the environment. Within these theories, there is no discussion of the role of norms in decision making. In criminological theories, in contrast, the normative environment is 
one of the factors which shapes people's preferences. Thus, while economic theory conceives of the deterrence effect in a narrow sense - the effect of law enforcement on the outcomes of actions - the deterrence effect can be seen from a broader perspective as comprising any factors which exert a preventative force against crime, either by influencing the gains associated with crime or by influencing norms.

In summary, the impact of an increase in the probability of a sanction on the supply of crime is dependent upon the assumptions employed by the models, though reasonable assumptions suggest that an increase in the probability of a sanction will reduce the supply of crime. However, the impact of increases in the severity of sanctions on the supply of crime is less clear-cut. Depending on individuals' attitude towards risk, and whether the model employed allows all the costs and benefits of legal and illegal activities to be monetised, an increase in the severity of a sanction could produce either an increase or a decrease in the supply of crime.

The implication of the theoretical models developed by economists is that accepting or rejecting the hypothesis that the prospect of imprisonment has a deterrent effect depends on assumptions about the nature of individuals' attitude towards risk. If it is accepted that individuals are risk averse and also that all social and psychological effects can be monetised, then crime is deterred by increases in the probability and (less certainly) by the severity of punishment. However, if either of these starting points is rejected, then the deterrence effect of prison or any other sanction is indeterminate.

\section{Empirical Studies of Deterrence}

In their examination of deterrence, economists have not relied entirely on theoretical models. Attempts to empirically estimate the deterrent effect of the probability and severity of punishment tend to support the conclusions of the theoretical models outlined above. While most economists and criminologists would probably agree that the empirical evidence supports the conclusion that an increase in the probability of sanction will lead to a decrease in crime, the evidence on sentence severity is more equivocal.

For example, Von Hirsch et al.'s (1999) survey of the literature on 'marginal deterrence' is equivocal about the deterrence effect of increasing the severity of punishment. Marginal deterrence is the effect of making changes to the certainty or severity of punishment. The evidence suggests that, while there may be some additional incapacitative or marginal deterrence effect from increasing the use of imprisonment, increasing the actual and perceived risk of being caught is a more effective, and more cost-effective, way of securing crime reduction (Von Hirsch et al. 1999). They conclude that 'the studies reviewed do not provide a basis for inferring that increasing the severity of sentences generally is capable of enhancing deterrent effects' (p.1). 
Eide (1999) interprets the empirical literature as corresponding with the theoretical literature outlined in the previous section. That is, the variation in the relationship between severity of punishment and offending identified in the empirical literature can be explained by variations in the proportion of risk-lovers in the population. Eide (1999) summarises the empirical literature and concludes that: 'in some studies the effect of an increase in the severity of punishment is not statistically different from zero, and a statistically significant positive effect has also occasionally been obtained' (p.360).

However, a counter view on the divergence in findings is that they are the result of a failure in research design in that the theoretical model being tested is not always properly operationalised. Mendes and MacDonald (2001) challenge Von Hirsch et al.'s findings and argue that they are 'a consequence of theoretical slippage when moving from a verbal theoretical statement to the statistical representation of that statement' (p.589). In essence they argue that deterrence is a theory in which the component parts (certainty of punishment and severity of punishment) are interrelated and inter-dependent. They contend that this is how the theory of deterrence was conceptualised by Becker (1968) but not all subsequent research has followed this approach.

Mendes's and MacDonald's (2001) review of existing empirical studies of deterrence concluded that: 'published empirical studies that fail to find a significant impact of the severity of punishment do not effectively translate the theory' (p.606). Further, when the theory is effectively translated as a 'package' composed of three elements: arrest, conviction and punishment, then the severity of punishment does represent an important role in implementing that package.

Even if we accept Mendes's and MacDonald's (2001) argument that a lot of empirical analysis of deterrence effects have used mis-specified models there remains some ambiguity about the relationship between sentence severity and crime rates. In their review Mendes and MacDonald found 16 studies that identified an effect of severity of punishment on offending and seven studies that did not.

In summary, the findings of the empirical literature on the deterrence effect mirrors that of the theoretical literature in that it supports the existence of a relationship between the probability of punishment and offending rates, but suggests an ambiguity about the impact of sentence severity on crime.

\section{Retribution?}

Of the different effects of prison outlined in the introductory section, CBA measures the incapacitation, rehabilitation, and specific deterrence effects, and economic theory and econometric analytical techniques have been applied to understand the general deterrence effect. There is very limited economic evidence on the remaining effect, retribution. The authors are aware of only one economic study that addresses this question. This study, by Nagin et al. (2006), elicited people's willingness to pay 
for two alternative policy interventions for drug-using offenders: adding a rehabilitative component (drug treatment) to a one-year prison sentence; and increasing the period of incarceration from one year to two years.

Respondents in Pennsylvania were randomly assigned to give their willingness to pay for one of the interventions. Other than the differences in the length of sentence and the availability of treatment, the description of the interventions was identical. For instance, in each case it was explained to respondents that the effect of the intervention would be to reduce youth crime by $30 \%$ and that youths in the programmes are also more likely to graduate from school and get jobs.

Based on approximately 4.8 million Pennsylvanian households, the authors estimated total willingness to pay to be between $\$ 387$ million and $\$ 468$ million for a $30 \%$ reduction in youth crime. Although Nagin and his colleagues did not translate the public's willingness to pay into a cost per crime, Cohen (forthcoming) subsequently attempted this calculation. He estimated a willingness-to-pay value for one avoided serious crime of $\$ 100,000$ in the case of the extended period of incarceration and $\$ 125,000$ in the case of the rehabilitative intervention.

Given that the interventions were presented as having the same crime-control benefit (that is, the interventions have the same incapacitation, rehabilitation, and deterrence effect), this experiment might be interpreted as estimating the value that the public (at least in Pennsylvania) places on the retributive effect of incarceration. More precisely, the fact that respondents were willing to pay more for the less retributive intervention would suggest that retribution is not valued as highly when set against the other aims of sentencing.

However, Cohen (forthcoming) points to a number of caveats to drawing this conclusion. For instance, while the two interventions were presented as being the same in their crime-control benefits and their impacts on future educational attainment and employment rates, it might be possible that the responses elicited are still picking up people's expectations that rehabilitative interventions produce better outcomes than incarceration. It is also important to recognise that there are various biases inherent in willingness-to-pay studies that may undermine this result. In particular, participants may respond differently to the hypothetical scenarios proposed in the studies from how they would respond if faced with the same problem in real life. Further detail of the challenges associated with such studies is available in Carson (2007).

\section{Discussion}

Recent increases in the prison population in the UK and the resulting prison overcrowding has given renewed vigour to the debate about whether incarceration is an appropriate response to offending. An important part of this 
debate is whether prison represents an efficient use of public resources. In order to answer this question, the article summarises the economic evidence on the costs and benefits of prison.

Several examples of the CBA of prison are identified in the literature. These suggest that prison is an inefficient sentencing option, but where the analysis differentiates between offender types it suggests that prison may be efficient for more serious offenders. However, a key limitation to this analysis is that it is able to capture only certain of the effects of prison. Specifically, it captures the incapacitation, rehabilitation and specific deterrence effects of prison, but is unable to capture the general deterrence and retribution effects. Given that this analysis suggests that prison is generally an inefficient use of resources when these effects are not considered the question becomes whether there is evidence for the general deterrence and retribution effects of prison, and, if so, whether these effects are large enough that the use of prison becomes an efficient use of resources.

Economists have built theoretical models and undertaken econometric analysis to determine whether the probability and severity of punishment impacts on the likelihood of offending. Both of these bodies of work suggest that an increase in the probability of punishment has a reductive effect on offending rates, but that there is an ambiguous relationship between the severity of punishment and offending. The theoretical models developed by economists suggest that whether severity of punishment impacts on offending is dependent upon the individuals' attitudes towards risk. If it is accepted that individuals are risk averse and also that all social and psychological effects can be monetised, then crime is deterred by increases in the probability and severity of punishment. However, if either of these starting points is rejected, then the deterrence effect of the severity of sanction is indeterminate. Given that the decision to incarcerate offenders is related to the severity of punishment, the literature would suggest that the deterrence effect of prison is equivocal and depends on the degree to which the relevant population is risk averse.

The review identified only one economic study that relates to the final effect of prison: retribution. While this suggests that the public does not place much value on the retributive effect of incarcerating offenders, there were limits to the conclusions that could be drawn about the existence or magnitude of the retributive effect.

This article also points to some important gaps in the economic evidence that need filling to appropriately inform decisions on sentencing policy. First, more CBA is required to determine the relative efficiency of types and lengths of sentence for different offenders in the UK. Second, econometric analysis is required to determine whether prison is likely to have a general deterrent effect in the UK. Third, very little is known about the retributive effect of prison. Despite these reservations about the state of the evidence, it is reasonable to conclude from the existing costbenefit evidence that while prison may be an efficient sentencing option for more serious offenders, for non-serious offenders the cost outweighs the benefit of the 
incapacitation, rehabilitation and specific deterrence effects. While the evidence on general deterrent and retributive effects is limited, the evidence that is available concurs with this assessment. Whatever the other reasons put forward for or against the use of prison, it is reasonable to conclude that using it for anyone but those convicted of serious offences is a waste of public resources.

Notes

1 Hedderman and Hough (2005) explain, regression to the mean involves extreme scores in the first observation shifting towards the mean on subsequent observations.

2 See, for example, Hopkins Burke (2005) for an overview of the history of rational choice theory within criminology. 


\section{References}

Aos, S., Phipps, P., Barnoski, R. and Lieb, R. (2001) The Comparator Costs and Benefits of Programs to Reduce Crime, Olympia: Washington State Institute for Public Policy.

Aos, S., Miller, M. and Drake., E. (2006) Evidence-Based Public Policy Options to Reduce Future Prison Construction, Criminal Justice Costs, and Crime Rates, Olympia: Washington State Institute for Public Policy.

Barnett, W.S. and Escobar, C.M. (1987) 'The economics of early educational interventions: a review', Review of Educational Research, 57(4), 387-414.

Becker, G.S. (1968) 'Crime and punishment: an economic approach', Journal of Political Economy, 76(2), 169-217.

Bottoms, A.E. (2004) 'Empirical research relevant to sentencing frameworks', in: A. Bottoms, S. Rex and G. Robinson (Eds.), Alternatives to Prison: Options for an Insecure Society, Cullompton: Willan.

Bowers, K., Johnson, S.D. and Hirschfield, A.F.G. (2004) 'Closing off opportunities for crime: an evaluation of alleygating', European Journal on Criminal Policy and Research, 10(4), 285-308.

Brown, D.K. (2004) 'Cost-benefit analysis in criminal law', California Law Review, 92(2), 325-72.

Bushway, S. and Reuter, P. (2005) 'Collaborating with economists', The Criminologist, 30(1), 1-4.

Carson, R.T. (2007) Contingent Valuation: A Comprehensive Bibliography and History, Northampton, MA.: Edward Elgar.

Carter, P. (2003) Managing Offenders, Changing Lives: A New Approach, London: Home Office.

Cohen, M.A. (2000) 'Measuring the costs and benefits of crime and justice', in: D. Duffee (Ed.), Criminal Justice 2000: Measurement and Analysis of Crime and Justice, vol. 4, Washington, DC.: National Institute of Justice.

Cohen, M.A. (forthcoming), 'Valuing crime control benefits using stated preference approaches', in: T. Dunworth, J. Roman, K. Marsh and J. Mallender (Eds.), CostBenefit Analysis of Criminal Justice Interventions, Washington, DC.: Urban Institute Press. 
Dhiri, S. and Brand, S. (1999) Analysis of Costs and Benefits: Guidance for Evaluators, London: Home Office, RDS.

Dilulio, J. (1996) 'Help wanted: economists, crime, and public policy', Journal of Economic Perspectives, 10, 1-23.

Eide, E. (1999) 'The economics of criminal behaviour', in: B. Bouckaert and G. DeGeest (Eds.), Encyclopedia of Law and Economics, V. The Economics of Crime and Litigation, Cheltenham: Edward Elgar.

Friendship, C., Street, R., Cann, J. and Harper, G. (2004) 'Introduction: the policy context and assessing the evidence', in: G. Harper and C. Chitty (Eds.), The Impact of Corrections on Re-offending: A Review of 'What Works' (Home Office Research Study 291), London: Home Office.

Gray, T. and Olson, K.W. (1989) 'A cost benefit analysis of the sentencing decision for burglars', Social Science Quarterly, 70, 708-22.

Hedderman, C. (2007) 'Past, present and future sentences: what do we know about their effectiveness?', in: L.R. Gelsthorpe and R. Morgan (Eds.), The Probation Handbook, Cullompton: Willan.

Hedderman, C. (2008) Building on Sand: Why Expanding the Prison Estate is Not the Way to 'Secure the Future' (Briefing 7), London: Centre for Crime and Justice Studies.

Hedderman, C. and Hough, M. (2005) 'Diversion from prosecution at court and effective sentencing', in: A.E. Perry, C. McDougall and D.P. Farrington (Eds.), Reducing Crime: The Effectiveness of Criminal Justice Interventions, Chichester: Wiley.

Hopkins Burke, R. (2005) An Introduction to Criminological Theory, Cullompton: Willan.

Marsh, K., Chalfin, A. and Roman, J. (2008) 'What does economic analysis add to decision making? Evidence from the criminal justice literature', Journal of Experimental Criminology, 4(2), 117-35.

Marsh, K. and Fox, C. (2008) 'The benefit and cost of prison in the UK: the results of a model of lifetime re-offending', Journal of Experimental Criminology, 4(4), 403-23.

McDougall, C., Cohen, M., Swaray, R. and Perry A. (2003) 'The costs and benefits of sentencing: a systematic review', Annals of the American Academy of Political and Social Science, 587, 160-77. 
Mendes, S. and MacDonald, M. (2001) 'Putting severity of punishment back in the deterrence model', Policy Studies Journal, 29(4), 588-610.

Nagin, D.S. (1998) 'Deterrence and incapacitation', in: M. Tonry (Ed.), The Handbook of Crime and Punishment, New York: Oxford University Press.

Nagin, D.S. and Paternoster, R.A. (1993) 'Enduring individual differences and rational choice theories of crime', Law and Society Review, 27(3), 467-96.

Nagin, D.S., Piquero, A.R., Scott, E.S. and Steinberg, L. (2006) 'Public preferences for rehabilitation versus incarceration of juvenile offenders: evidence from a contingent valuation survey', Criminology and Public Policy, 5, 627-52.

NICE (2007) Guidelines Development Manual, London: The National Institute for Health and Clinical Excellence. Available at: http://www.nice.org.uk/niceMedia/pdf/ GuidelinesManualAllChapters.pdf (accessed 8 August 2008).

Parks, G. (2000) The High/Scope Perry Preschool Project Office of Juvenile Justice and Delinquency Prevention Justice bulletin, October 2000. Available at: http:// www.ncjrs.gov/html/ojjdp/2000_10_1/contents.html (accessed 16 May 2008).

Piehl, A.M. and Dilulio, J.J., (1995) 'Does prison pay? Revisited', The Brookings Review, 13, 21-5.

Roman, J. and Butts, J.A. (2005) The Economics of Juvenile Jurisdiction, Washington, DC.: Urban Institute.

Swaray, R.B., Bowles, R. and Pradiptyo, R. (2005) 'The application of economic analysis to criminal justice interventions: a review of the literature', Criminal Justice Policy Review, 16(2), 141-63.

Trasler, G. (1993) 'Conscience, opportunity, rational choice and crime', in: R.V. Clarke and M. Felson (Eds.), Routine Activity and Rational Choice: Advances in Criminological Theory, vol. 5, New Brunswick, NJ.: Transaction Books.

von Hirsch, A., Bottoms, A., Burney, E. and Wikstro"m, P.-O. (1999) Criminal Deterrence and Sentence Severity: An Analysis of Recent Research, Oxford: Hart. Available at: http://rds.homeoffice.gov.uk/rds/pdfs/crimdet.pdf (accessed 8 August 2008).

Welsh, B. and Farrington, D.P. (2000) 'Monetary costs and benefits of crime prevention programs', Crime and Justice, 27, 305-61. 